\title{
Role of the Endocannabinoid System and Medical Cannabis
}

Sabrina Jarvis

Brigham Young University, sabrina-jarvis@byu.edu

Sean Rasmussen

Brigham Young University, sirsiras@hotmail.com

Blaine Winters

Brigham Young University - Provo

Follow this and additional works at: https://scholarsarchive.byu.edu/studentpub

Part of the Nursing Commons

The College of Nursing showcases some of our best evidence based scholarly papers from graduate students in the Family Nurse Practitioner Program. The papers address relevant clinical problems for advance practice nurses and are based on the best evidence available. Using a systematic approach students critically analyze and synthesize the research studies to determine the strength of the evidence regarding the clinical problem. Based on the findings, recommendations are made for clinical practice. The papers are published in professional journals and presented at professional meetings.

\section{BYU ScholarsArchive Citation}

Jarvis, Sabrina; Rasmussen, Sean; and Winters, Blaine, "Role of the Endocannabinoid System and Medical Cannabis" (2016). Student Works. 192.

https://scholarsarchive.byu.edu/studentpub/192

This Master's Project is brought to you for free and open access by BYU ScholarsArchive. It has been accepted for inclusion in Student Works by an authorized administrator of BYU ScholarsArchive. For more information, please contact scholarsarchive@byu.edu, ellen_amatangelo@byu.edu. 
Role of the Endocannabinoid System and Medical Cannabis

\section{Sean I. Rasmussen}

An evidence based scholarly paper submitted to the faculty of Brigham Young University in partial fulfillment of the requirements for the degree of

Masters of Science

Sabrina Jarvis, Chair

Blaine Winters

College of Nursing

Brigham Young University

Copyright (C) 2016 Sean I. Rasmussen

All Rights Reserved 


\author{
ABSTRACT \\ Role of the Endocannabinoid System and Medical Cannabis \\ Sean I. Rasmussen \\ College of Nursing, BYU \\ Master of Science
}

Our bodies produce substances called endocannabinoids which attach to receptors within the endocannabinoid system (ECS) impacting physiological processes on a daily basis. The cannabis plant contains over 100 different cannabinoids which also manipulate the ECS. Knowledge about these interactions have led to an increase in cannabis based pharmacological studies. Providers should have a basic understanding about how the ECS works and how cannabis is being used to treat certain illnesses. This article presents what is currently known about the ECS and how cannabis based medicines impact it, as well as the current laws providers need know regarding cannabis use.

Keywords: Cannabis, Endocannabinoids, Cannabinoids, ECS, CB1, CB1, CB2 



\section{TABLE OF CONTENTS}

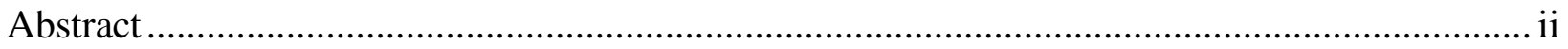

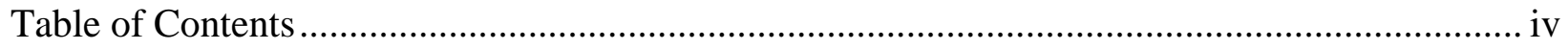

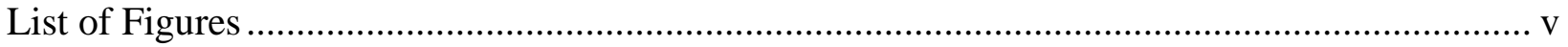

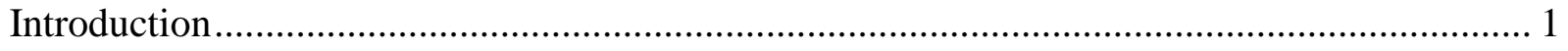

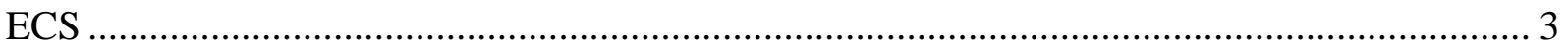

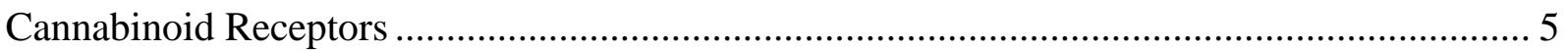

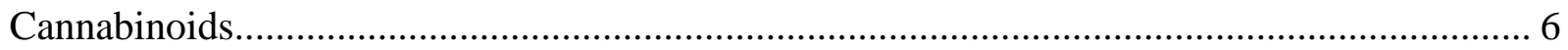

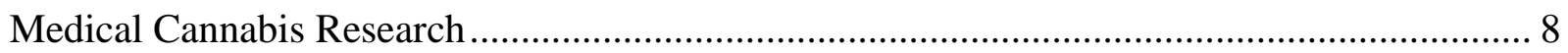

Health-Care Provider Concerns ................................................................................... 10

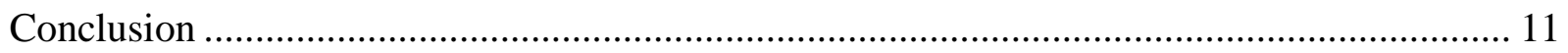

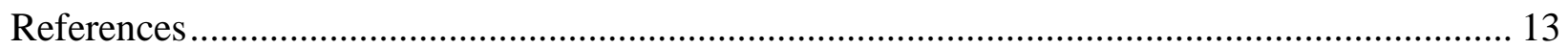




\section{LIST OF FIGURES}

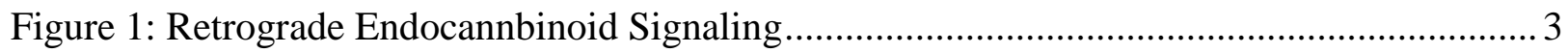




\section{Introduction}

Cannabis has been highly valued and used by many cultures, throughout history, for its medicinal, euphoria, and relaxing enhancing properties. This usage dates back over 3000 years with the report of anxiety relief with bhang (cannabis consumed as food) in ancient India ${ }^{1}$. In 2008, archeologists discovered cannabis in 2,500 year-old tombs in Eastern China. Genetic testing of this ancient marijuana led researchers to believe that not only was the marijuana used for treating illness but was used for its psychotropic effects and for spiritual purposes as well ${ }^{2}$.

It was not until much later that cannabis was introduced into the United States. In 1619, King James I ordered the Jamestown colonists to grow cannabis plants for hemp export. The hemp fibers were used to manufacture ropes, paper, and fabric ${ }^{3}$. In the 1850 's, medicinal preparations became available in American pharmacies. Over the next 3 decades, recreational use of cannabis flourished in oriental-style hashish establishments ${ }^{4}$. It was during this time that cannabis was labeled as both a poison and narcotic.

In 1906, the Pure Drug and Food Act was passed requiring that certain drugs, including cannabis, be accurately labeled and states began to restrict the sale of cannabis ${ }^{5}$. In 1937 , the Marijuana Tax Act was passed which made it illegal to possess or transfer cannabis. In 1970, the Supreme Court determined that the Marijuana Tax Act was unconstitutional. It was during this time Congress passed the Controlled Substance Act and listed cannabis as a Schedule 1 drug 6 .

Cannabis possesses over 100 different cannabinoids and has been found to modulate analgesia and anti-inflammatory pathways and provide neuroprotection among other functions ${ }^{7}$. In the 20th century, $\Delta 9$-tetrahydrocannabinol (THC) was identified as a primary bioactive component of cannabis; this led to the discovery and cloning of endogenous cannabinoid receptors. It was also found the body could produce naturally occurring substances, called 
endocannabinoids, which could mimic THC activity. Endocannabinoids, their receptors, and the associated mediating enzymes for synthesis and degradation comprise the endocannabinoid system $(\mathrm{ECS})^{8}$.

In the United States there are three categories of cannabinoid medicines: single molecule drugs, cannabis-based liquid extracts, and phytocannabinoid botanicals ${ }^{7}$. Single molecule drugs are semi-synthetic or synthetic prescription drugs. The U.S. Food and Drug Administration (FDA) have approved two of these and they are nabilone and dronabinol ${ }^{7}$. The second category of cannabis-based liquid extracts includes the botanical drug naximols which is produced by the UK- based GW Pharmaceuticals company. This drug is currently undergoing FDA phase 3 trials. They are looking at whether there is significant difference between naximols and placebo in reducing pain in patients with advanced cancer ${ }^{9}$.

The last category of cannabinoid medicines is phytocannabinoid botanicals which includes the Schedule 1 plant Cannabis sativa ${ }^{7}$. These are dense cannabis extracts which are usually put into capsule or pill form. Other methods of delivery may include through sublingual sprays, transdermal patches, suppositories and topical ointments. An example of this category is a schedule three drug called Idrasil which is used to help alleviate pain and improve appetite ${ }^{10}$.

With the discovery of the ECS, scientists and researchers have been petitioning to remove the cannabis Schedule I drug restrictions so medical research can more easily be done. Current research is studying the effects of exogenous cannabinoids in treating symptoms of epilepsy, HIV neuropathy, chemotherapy induced nausea, anorexia, multiple sclerosis spasticity, chronic and neuropathic pain, glaucoma intraocular pressures, and asthma-associated dyspnea ${ }^{7}$. The FDA has recently given approval for a study on the effect of medical cannabis on treating military veterans with post-traumatic stress disorder ${ }^{11}$. 
Currently, twenty-five states have passed laws permitting limited use of medicinal cannabis for specific medical conditions ${ }^{12}$. Patients receive state authorizations to procure and self-administer medicinal cannabis under in-state medical supervision. Yet many health-care providers feel uncomfortable providing care to these patients. Besides geographical considerations, there continues to be a sociopolitical environment in which state laws are in direct conflict with federal laws with potential serious legal consequences to both provider and patient $^{12}$. The purpose of this article is to educate health-care professionals about the ECS and the research being done on medications which directly impact the ECS to reduce or alleviate disease-associated symptoms. Additional background information will be provided on current cannabis plant medical research and the sociopolitical factors which continue to impact both the health care provider and patient in the decision to treat with cannabinoid medications.

\section{ECS}

The ECS is comprised of endocannabinoids (eCBs), their receptors, and the associated

Figure 1. Retrograde Endocannbinoid Signaling

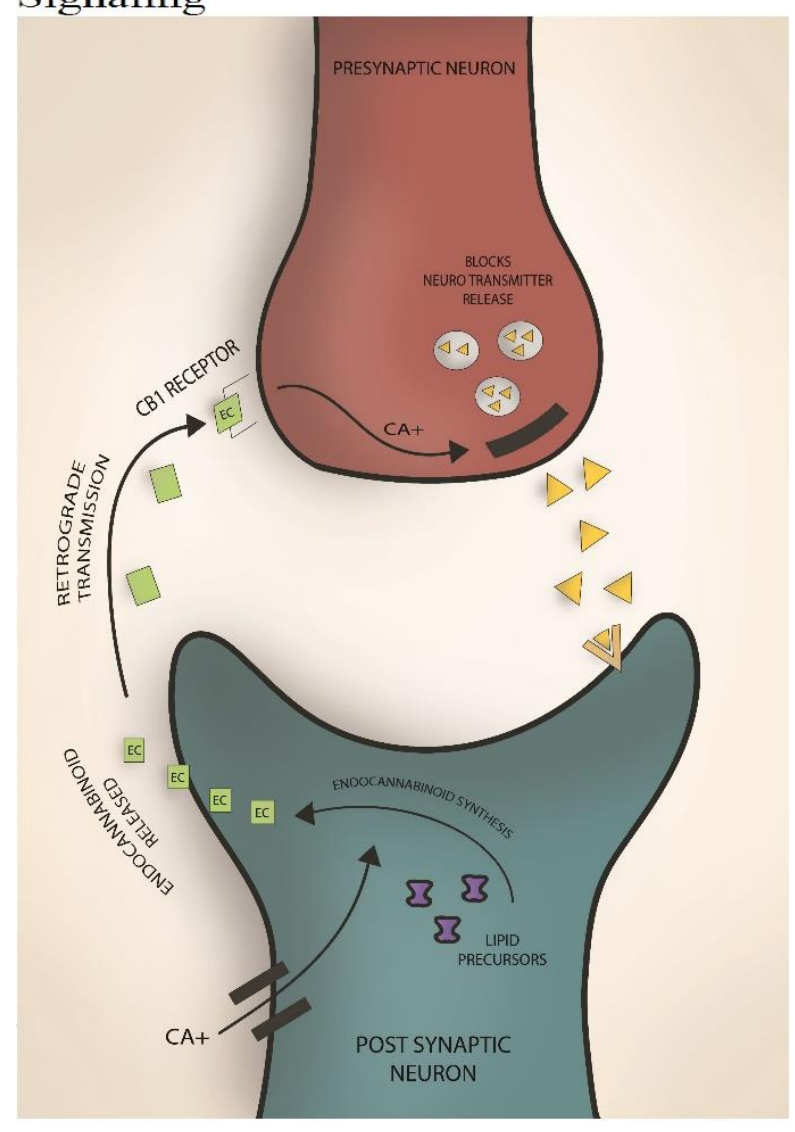

mediating enzymes for synthesis and degradation. It is a unique and complex system with the endocannabinoids acting as the only known retrograde synaptic neurotransmitters ${ }^{13}$. There are five known eCBs produced by the body. They include: Anandamide (AEA), 2Archidonoyl glyceral (2-AG), 2-Archidonoyl glyceral ether (noladin ether), O- Archidonoyl ethanolamine (virodhamine), and $\mathrm{N}$ Arachidonoyl dopamine ${ }^{13}$. AEA and 2-AG are 
the two most commonly recognized and studied endocannabinoid ligands and are endogenous arachidonate-based lipids ${ }^{14}$. AEA was discovered in 1992 and helped to provide a basic understanding of ECS neuro-modulating function. AEA's effects occur in both the central nervous system and the peripheral nervous system. There is less information on noladin ether, virodhamine, and $\mathrm{N}$-Arachidonoyl dopamine and their roles in the regulation of the ECS ${ }^{15}$. It is important to note eCBs are normally at low levels when body homeostasis is balanced. They only begin to be synthesized in large quantities when stimulated. This activation can occur as a response to painful stimuli, bacterial and/or viral infections, stress response, or inflammation ${ }^{16}$. While cannabis plant cannabinoids directly target cannabinoid Type 1 receptors (CB1Rs) on the pre-synaptic neuron, AEA and 2-AG are produced, on demand, from lipid precursors found in the post-synaptic neuron and released into the synaptic space (Figure 1). When depolarization of the postsynaptic neuron occurs, the naturally influxed calcium is thought to activate the enzyme, transacyclase. It is suggested this enzyme catalyzes the first step in the biosynthesis of endocannabinoids by converting phosphatidylethanolamine, a phospholipid, into N-acyl-phosphatidlethanolamine (NAPE). The endocannabinoids then travel retrograde to the $\mathrm{CB} 1$ receptors on the presynaptic neuron. The bound endocannabinoids initiate a series of biochemical reactions which lead to a decrease in inhibitory neurotransmitters (Figure 1). This leads to the direct result of increased activity of the postsynaptic neuron. The AEA is then rapidly inactivated by fatty acid amide hydrolase (FAAH) and the 2-AG is broken down by monoacylglycerol lipase ${ }^{17}$.

The primary purpose of the ECS is to provide homeostasis for many metabolic functions such as neurotransmitter, inflammation and energy modulation. The ECS is located throughout the entire body and is comprised of specific cannabinoid receptors. 


\section{Cannabinoid Receptors}

The cannabinoid receptors are $\mathrm{G}$ protein-coupled receptors which are activated by three major groups of ligands: endocannabinoids produced by the body, cannabinoids produced from the cannabis plant, and synthetic cannabinoids. The two principle subtypes of cannabinoid receptors are CB1Rs and cannabinoid Type 2 receptors (CB2Rs) ${ }^{18}$.

CB1Rs reside heavily within the central nervous system (CNS) and are well known for their neurological effects when activated. In addition to their presences within the brain, CB1Rs are also found within digestive organs, including the pancreas, liver, small intestines, and large intestines. They have also been found within muscle fibers and adipocyte cells as well ${ }^{16}$. Although CB1Rs are scattered throughout the body their role and function within the CNS may hold the most potential.

CB1Rs found within the hippocampus and limbic system play a significant role in the regulation of emotions. When the hippocampus receptors are activated, cannabis users often describe experiencing a blissful euphoria ${ }^{16}$. Clinical data suggests endocannabinoids and CB1Rs may modulate anxiety and depression. Augmentation of the endocannabinoid signaling has been found to decrease depression and anxiety symptoms, whereas, if the CB1Rs are blocked, this produces increased symptoms ${ }^{19}$. There are also CB1Rs located in the basal ganglia and hypothalamus, which when stimulated, help regulate appetite and gastric motility. These gastric effects led to the development of dronabinol, a medication used to treat cancer-related anorexia and nausea symptoms ${ }^{16}$.

CB2Rs are found in many areas in the body and, unlike CB1Rs, have almost no psychoactive effects when stimulated. Most are found along the spinal column or in the bone marrow while only a few receptors are found within the brain ${ }^{16}$. Although both CB1Rs and 
CB2Rs have been found in inflammation leukocyte mediators, CB2Rs are predominant in leukocytes and appear to be the key mediators of cannabinoid regulation of the immune and inflammatory systems. When the CB2Rs are blocked, there is inhibition of splenocyte production and in vivo cell death. When macrophage CB2Rs are stimulated they inhibit proliferation and the release of pro-inflammatory factors, and decrease phagocytosis ${ }^{20}$. For example, in the presence of ischemia, cardiomyocytes are subject to inflammation and eventually cellular death. In this state CB2Rs are agonized as part of the body's natural response. When researchers antagonized CB2Rs during hypoxia, both inflammation and macrophage digestion was minimized ${ }^{21}$.

CB1Rs and CB2Rs play a role in modulating pain pathways and helping to provide analgesia. In cancer pain pathway research, cannabinoids act as analgesics in patients with neuropathic pain and are antihyperalagesic. They have been shown to decrease painful stimuli from sensory neurons in many animal models. There are also indications cannabinoids may potentiate the analgesic properties of morphine and help prevent drug tolerance ${ }^{22}$.

In neuropathic pain, cannabinoids act on peripheral and central nerve CB1Rs and keratinocytes CB2Rs. The peripheral nociceptors CB1Rs help mediate and block painful stimuli to the sensory neurons. CB2Rs located on the immune cells and keratinocytes stimulates $\beta$ endorphin release and decreased pain stimuli through $\mu$-opiod receptors ${ }^{22}$.

\section{Cannabinoids}

The cannabis plant contains over 400 naturally occurring chemicals and approximately 100 cannabinoids ${ }^{23}$. Cannabis is the root word and the scientific plant genus from which all other names derive. There are three subspecies of cannabis including cannabis sativa, cannabis indica, and cannabis ruderalis. Cannabis sativa is the most widely cultivated plant in the US and abroad for both commercial and pharmaceutical uses ${ }^{24}$. 
The cannabis plant can be broken down into four major parts which are the stems, seeds, flowers or buds, and leaves. Hemp is obtained from the stems and is used to manufacture clothing, rope, paper, protein supplements, beauty products, and oils. There is no abuse potential or medicinal benefit from hemp or hemp products ${ }^{24}$.

Female flowers produce recreational and medicinal drugs, edible seeds, and essential oils ${ }^{24}$. Dried leaves and flowers are smoked for their euphoric and relaxing enhancing properties ${ }^{24}$. Cannabidiol (CBD) and, $\Delta$ 9-tetrahydrocannabinol (THC) are the most commonly researched cannabinoids. In 1940, CBD was extracted from the cannabis plant and was found to have no psychotropic effects $^{25}$. In 1964, THC, the primary psychotropic cannabinoid, was discovered and ECS research gained momentum ${ }^{14}$.

CBD targets CB2Rs with an agonizing effect. Since CBD has very little impact on CB1Rs, the psychoactive side effects are minimized. Colorado researchers manipulated cannabis plant genetics to remove THC in an attempt to develop pediatric epilepsy medical cannabis. The cannabis was found to be ineffective. It was discovered the cannabinoids work better together and produce a synergistic effect which leads to improved clinical outcomes ${ }^{26}$.

This finding led to the development of the specialized medical cannabis, Charlotte's Web, which is an example of medical cannabis high in CBD and low in THC (<.3\%). This unique formula maintains better seizure control with minimal psychoactive side effects ${ }^{26}$.

Since 2014, GW Pharmaceuticals has been testing another medical cannabis drug called Epidiolex which has a 99\% CBD concentration and $<10 \%$ THC content. It is being used to treat Dravet Syndrome which is a rare form of epilepsy. In March 2016, the company reported its Phase 3 Clinical Trials which showed some promising results. They reported almost a $40 \%$ decrease in monthly convulsive seizures among their participants ${ }^{27}$. Their study was performed 
on children between the ages of 6-10 who had previously been on multiple anticonvulsants which had failed to adequately control their seizures. Their goal is to be the first cannabis based drug approved by the FDA for seizure control in children with epilepsy ${ }^{27}$.

\section{Medical Cannabis Research}

Besides research on the use of cannabinoids as anticonvulsant agents, many other ECS research studies are being done. Animal model research suggests the ECS may have an important role in the creation, maintenance, and expenditure of energy ${ }^{16}$. Another study linked CB1Rs to the health and maintenance of kidneys ${ }^{28}$. The study revealed that kidney fibrosis, which often occurs in kidney disease and diabetes, was worse in the presence of CB1R activation in kidney tissues. In mice, when CB1Rs were blocked, it resulted in a significant decrease in kidney fibrosis and renal scarring ${ }^{28}$. Some researchers believe medical conditions, such as weight loss and diabetes, may someday be controlled through CB1R manipulation ${ }^{16}$.

According to a recent clinical review, compelling evidence suggests medical cannabis may show promise in areas of chronic pain and spasticity associated with multiple sclerosis. Both of these conditions would use THC as the primary effector ${ }^{23}$.

Recent research is examining the role of CB1Rs and cannabinoids in the treatment of Post-Traumatic Stress Disorder (PTSD) in the veteran population. There are known elevated numbers of brain CB1Rs associated with PTSD ${ }^{29}$. Currently there is a $\$ 2,156,000$ grant research project, the Marijuana for Symptoms of PTSD in U.S. Veterans, being carried out ${ }^{30}$.

Other research is examining the effects of THC on the treatment of memory loss and Alzheimer's disease. Animal model research demonstrates THC competitively inhibits the enzyme acetylcholinesterase and decreases amyloid $\beta$-peptide aggregation which is a key marker of Alzheimer's disease ${ }^{31}$. 
Cannabinoids and their receptors are also being studied for their roles in cancer tumor growths. Animal tumor models suggest endocannabinoids may inhibit neo-angiogenesis and tumor cell migration. These actions may be receptor-independent based on the type of tumor or tissue cell and the cannabinoid or endocannabinoid expressed ${ }^{32}$.

In order for these studies to take place cannabis need to be legally grown, harvested and supplied to research institutions here in the US. Over the years, researchers have struggled gaining access to medical cannabis in order to complete these studies. Medical cannabis has been used for research and clinical trials in animals, but human studies have been restricted by cannabis' Schedule 1 drug listing under federal law and the negative stigmatism cannabis among the general population. This severely limited the availability of research grown cannabis. Since the 1960's, the federal government has only approved the University of Mississippi's (U of M) School of Pharmacy to grow cannabis. In 2013, U of M had about 34 pounds of medical cannabis available for researchers. Today there are over twelve acres and an indoor nursery, which together, provide about 1400 pounds of cannabis grown solely for medical research and scientific studies ${ }^{26}$. With the significant increase in cannabis research, Drug Enforcement Administration is again reviewing the possibility of changing cannabis from a Schedule 1 to a Schedule 2 drug classification ${ }^{33}$.

The botanists at the University of Mississippi work closely with pharmaceutical companies and researchers in order to provide crops to meet their unique and specific needs for the illness they are targeting. The scientists genetically modify the cannabis plant concentrations of $\mathrm{THC}$ and $\mathrm{CBD}^{26}$. Once the cannabinoid strains are chosen and procured for medical use, drug companies must then decide on the mechanism of delivery and which biochemical form they would like to use. 


\section{Health-Care Provider Concerns}

If research continues in the direction it is heading, then providers will need to decide how they want to proceed if asked to prescribe cannabis-based drugs. There are numerous concerns regarding cannabis use if laws and regulations remain the same. Providers may face certain challenges should they choose to prescribe cannabis for their patients. For example, as long as federal law defines cannabis as a Schedule I drug then states which have legalized cannabis are in direct conflict with federal law. Today, medical cannabis is legalized in 25 states and the District of Columbia. Despite having state law approval, providers could be subject to prosecution according to federal laws. However, most federal law enforcement agencies have left the policing of in-state marijuana cases to state authorities, resulting in national prosecutors refraining from pursuing states and their medical providers who are currently prescribing medical cannabis ${ }^{34}$. Yet, this does not alleviate the risk a provider takes when prescribing medical cannabis since the federal government could decide to take a new position on enforcement at any time ${ }^{35}$.

Health care providers must also be concerned with state specific regulations. In states where medical cannabis use has been legalized, there is no medical practice standardization across state lines. Each state determines the medical conditions which may or may not be treated. Often these conditions include a handful of serious illnesses which have failed to respond to conventional treatment modalities. This makes it difficult to provide continuity of care to patients who have moved from one state to another. The provider must also be aware and compliant with the state mandated medical documentation requirements which include the frequency of reevaluation for the medical condition being treated. Many states also differ in who can prescribe cannabis. Some states may only allow certain specialists, such as neurologists and oncologists, to 
prescribe cannabis medications. Qualified providers then write a recommendation stating the patient would benefit from medical cannabis ${ }^{35}$. However, without FDA guidelines and the standardization of medical cannabis drugs, patients and providers are left to determine proper dosing regimens on their own.

Once patients receive their medication, struggles may persist as far as who can administer it and when it can be taken. The continued conflict between state and federal laws may put nurses and parents who administer medical cannabis at risk for legal prosecution. For example, Colorado is currently reviewing its laws on allowing students with valid prescriptions to use edible medicinal cannabis at public schools. The Colorado law states it is permissible for the school nurse or parent to administer the medicinal cannabis as long as the school district agrees. Currently no school district has given its approval. Additionally, school nurses are in conflict because they are required by federal law to report to authorities any child exposed to illegal drugs which include cannabis derived preparations ${ }^{36}$.

These regulatory inconsistencies between state and federal law leave many health care providers reluctant to offer cannabis based medicines even when it may be justified and the best available option for the patient. Providers also fear it puts the patient at risk since human research cannabis trials are limited and there is no standardization to medical cannabis drug regimens.

\section{Conclusion}

It is important for health care providers to understand the basic functioning of the ECS and its potential to treat many disease processes. Up to now medical cannabis research, with human subjects, has been limited by federal law and the availability of government sanctioned research on cannabis. As the interest in cannabis medical research increases, and involvement of 
pharmaceutical companies in developing cannabis based treatments grows, further research needs to be expanded to include human subjects. This comes at a time in American culture when there is a strong movement to discuss and legalize cannabis for both medical and recreational use. Currently, four states have legalized cannabis for recreational use while 25 states have laws sanctioning medical applications ${ }^{37}$.

This has led to continued state and national debates to change cannabis from a Schedule 1 to Schedule 2 drug. While states continue to legalize medical cannabis, there is inconsistency in law and policies and direct conflict with federal laws. It is hoped that a resolution will occur in which the federal government will allow quality cannabis medical research to be done to determine the actual value of cannabis in treating human disease processes.

Health care providers need to understand the legal ramifications of prescribing cannabisbased drugs. It is hoped as the conflict resolves and quality cannabis research is carried out. The ECS and cannabis-based drugs will offer new treatment options for patients with serious diseases refractory to conventional treatments. 


\section{REFERENCES}

1. Mechoulam R. The Pharmacohistory of Cannabis Sativa. Boca Raton, FL: CRC Press; 1986:1-19.

2. Russo E, Jiang H, Li X, Sutton A, Carboni A, Bianco F, et al. Phytochemical and genetic analyses of ancient cannabis from Central Asia. Journal Of Experimental Botany. 2008;59(15):4171-4182.

3. Deitch R. Hemp: American History Revisited: The Plant with a Divided History. New York: Algora Publishing; 2003:16.

4. Gieringer DH. The forgotten origins of cannabis prohibition in California. Contemporary Drug Problems. 1999;26(2):2-15.

5. Musto DF. The American Disease (3rd Edition) Origins of Narcotic Control. New York: Oxford University Press; 1999:3.

6. Nordrum A. Why is marijuana a schedule I drug? International Business Times. February 19, 2015. http://www.ibtimes.com/why-marijuana-schedule-i-drug-1821426. Accessed July 8, 2016.

7. Aggarwal S, Carter G, Sullivan M, ZumBrunnen C, Morrill R, Mayer J. Medicinal use of cannabis in the United States: historical perspectives, current trends, and future directions. Journal Of Opioid Management. May 2009;5(3):153-168.

8. Di Marzo V, Bifulco M, De Petrocellis L. The endocannabinoid system and its therapeutic exploitation. Nature Reviews Drug Discovery. 2004;3(9):771-784.

9. Pharmaceuticals GW. GW Pharmaceuticals and Otsuka Announce Results in First of Three Sativex(R) Phase 3 Cancer Pain Trials. https://globenewswire.com/newsrelease/2015/01/08/695898/10114614/en/GW-Pharmaceuticals-and-Otsuka-Announce- 
Results-in-First-of-Three-Sativex-R-Phase-3-Cancer-Pain-Trials.html. Updated January 8, 2015. Accessed July 2, 2016.

10. Idrasil. FAQ's. http://idrasilrx.com/faqs-2/. Accessed June 7, 2016.

11. Kime P. DEA approves PTSD marijuana study. Military Times. http://www.militarytimes.com/story/veterans/2016/04/21/dea-approves-ptsd-marijuanastudy/83356604/. April 23, 2016. Accessed July 11, 2016.

12. Office of National Drug Control Policy. Marijuana Resource Center: State Laws Related to Marijuana. https://www.whitehouse.gov/ondcp/state-laws-related-to-marijuana. Accessed July 24, 2016.

13. Gui H, Tong Q, Qu W, Mao C, Dai S. The endocannabinoid system and its therapeutic implications in rheumatoid arthritis. International Immunopharmocology. May 2015;26(1):86-91.

14. Maccarrone M, Bab I, Bíró T, Cabral GA, Dey SK, Di Marzo V, et al. Endocannabinoid signaling at the periphery: 50 years after THC. Trends in Pharmacological Sciences. May 2015;36(5):277-296.

15. Wilhelmsen K, Khakpour S, Tran A, Sheehan K, Schumacher M, Xu F, et al. The endocannabinoid/endovanilloid N-arachidonoyl dopamine (NADA) and synthetic cannabinoid WIN55,212-2 abate the inflammatory activation of human endothelial cells. The Journal of Biological Chemistry. March 1014;289(19):13079-13100.

16. Pacher P, Batkai S, Kunos G. The endocannabinoid system as an emerging target of pharmacotherapy. Pharmacological Reviews. 2006;58(3):389-462. doi:10.1124/pr.58.3.2.

17. Marzo V, Matias I. Endocannabinoid control of food intake and energy balance. Nature Neuroscience. April 2005;8:585-589. 
18. Lu H, Mackie K. An Introduction to the endogenous cannabinoid system. Biological Psychiatry. April 2016;79(7):516-525.

19. Patel S, Hillard CJ. Role of endocannabinoid signaling in anxiety and depression. Current Topics In Behavioral Neurosciences. 2009;1:347-71.

20. Ashton JC, Glass M. The cannabinoid CB2 receptor as a target for inflammation-dependent neurodegeneration. Current Neuropharmacology. 2007;5(2):73-80.

21. Heinemanna JC, Duerr GD, Keppel K, Breitbach M,Fleischmann BK, Zimmer A, et al. CB2 receptor-mediated effects of pro-inflammatory macrophages influence survival of cardiomyocytes. Life Sciences. October 2015;138:18-28.

22. Schmidt BL, Hamamoto DT, Simone DA, Wilcox GL. Mechanism of cancer pain. Molecular Interventions. 2010;10(3):164-178. doi:10.1124/mi.10.3.7.

23. Hill KP. Medical marijuana for treatment of chronic pain and other medical and psychiatric problems: A clinical review. JAMA. 2015;313(24):2474-2483.

24. Clarke, R, Merlin M. Introduction to the mulitpurpose plant cannabis. Cannabis : Evolution and Ethnobotany. University of California Press. Berkeley, US; 2013:1-24.

25. Burstein S. Cannabidiol (CBD) and its analogs: a review of their effects on inflammation. Bioorganic \& Medicinal Chemistry. 1 April 2015;23(7):1377-1385.

26. Gupta S. Weed 3: the marijuana revolution. CNN Special Report. http://www.cnn.com/specials/health/medical-marijuana. Accessed June 24, 2016.

27. GW Pharmaceuticals. GW Pharmaceuticals Announces Positive Phase 3 Pivotal Trial Results for Epidiolex® (Cannabidiol) in the Treatment of Lennox-Gastaut Syndrome. http://www.gwpharm.com/GW\%20Pharmaceuticals\%20Announces\%20Positive $\% 20 \mathrm{Phase} \%$ 
203\%20Pivotal\%20Trial\%20Results\%20for\%20Epidiolex\%20cannabidiol\%20in\%20the\%20 Treatment\%20of\%20Lennox-Gastaut\%20Syndrome.aspx. Accessed July 24, 2016.

28. Lecru L, Desterke C, Grassin-Delyle S, Chatziantoniou C, Vandermeersch S, Devocelle A. et al. Cannabinoid receptor 1 is a major mediator of renal fibrosis. Kidney International. July 2015;88(1):72-84.

29. Neumeister A, Normandin MD, Pietrzak RH, Piomelli D, Zheng MQ, Gujarro-Anton A, et al. Elevated brain cannabinoid cb1 receptor availability in posttraumatic stress disorder: A positron emission tomography study. Molecular Psychiatry. 2013;18(9):1034-1040. doi:10.1038/mp.2013.61.

30. Maps. Marijuana for Symptoms of PTSD in U.S. Veterans. http://www.maps.org/research/mmj/marijuana-us. Updated 2016. Accessed July 24, 2016.

31. Eubanks LM, Rogers CJ, Beuscher AE, Koobs GF, Olson AJ, Dickerson TJ, et al. A molecular link between the active component of marijuana and alzheimer's disease pathology. Molecular Pharmaceutics. 2006;3(6):773-777. doi:10.1021/mp060066m.

32. Hermanson DJ, Marnett LJ. Cannabinoids: endocannabinoids and cancer. Cancer Metastasis Reviews. 2011;30(3-4):599-612. doi:10.1007/s10555-011-9318-8.

33. Green S. DEA source confirms schedule II medical marijuana is in the works. Santa Monica Observer. http://www.smobserved.com/story/2016/07/04/news/dea-source-confirmsschedule-ii-medical-marijuana-is-in-the-works/1562.html. July 10, 2016. Accessed July 24, 2016.

34. FindLaw. Utah Marijuana Laws. http://statelaws.findlaw.com/utah-law/utah-marijuanalaws.html. Updated 2016. Accessed July 27, 2016. 
35. ProCon. 16 States With Laws Specifically About Legal Cannabidiol (CBD). http://medicalmarijuana.procon.org/view.resource.php?resourceID=006473. Updated March 17, 2016. Accessed July 26, 2016.

36. Wyatt K. Medical marijuana in schools? Colorado law allowing students to use edible pot at public schools getting a 2nd look. US New and World Report. http://www.usnews.com/news/us/articles/2016-04-11/pot-in-schools-debate-returns-tocolorado. Updated April 11, 2016. Accessed July 27, 2016.

37. Governing. State Marijuana Laws Map. http://www.governing.com/gov-data/statemarijuana-laws-map- medical-recreational.html. Updated May 25, 2016. Accessed July 27, 2016. 